\title{
Case Report \\ The Unexpected Pitter Patter: New-Onset Atrial Fibrillation in Pregnancy
}

\author{
Sarah White, Janna Welch, and Lawrence H. Brown \\ Dell School of Medicine, University of Texas at Austin, USA \\ Correspondence should be addressed to Janna Welch; drjannawelch@gmail.com \\ Received 10 March 2015; Accepted 31 March 2015 \\ Academic Editor: Aristomenis K. Exadaktylos
}

Copyright (c) 2015 Sarah White et al. This is an open access article distributed under the Creative Commons Attribution License, which permits unrestricted use, distribution, and reproduction in any medium, provided the original work is properly cited.

\begin{abstract}
Background. Atrial fibrillation is a relatively uncommon but dangerous complication of pregnancy. Emergency physicians must know how to treat both stable and unstable tachycardias in late pregnancy. In this case, a 40 -year-old female with a cerclage due to incompetent cervix and previous preterm deliveries presents in new-onset atrial fibrillation. Case Report. A previously healthy 40 year-old African American G2 P1 female with a 23-week twin gestation complicated by an incompetent cervix requiring a cervical cerclage presented to the emergency department with intermittent palpitations and shortness of breath for the past two months. EMS noted the patient to have a tachydysrhythmia, atrial fibrillation with rapid ventricular response. She was placed on a diltiazem drip, which was titrated to $15 \mathrm{mg} / \mathrm{hr}$ without successful rate control. Her heart rate remained in the $130 \mathrm{~s}$ and the rhythm continued to be atrial fibrillation with RVR. Digoxin was then added as a second agent, and discussions about the potential risks of cardioversion in pregnancy ensued. Fortunately, the patient converted to sinus rhythm before cardioversion became necessary. The digoxin was discontinued; the diltiazem was also discontinued after the patient subsequently developed hypotension. "Why Should Emergency Physicians Be Aware of This?" New-onset atrial fibrillation is rare in pregnancy but can increase the mortality and morbidity of the mother and fetus if not treated promptly.
\end{abstract}

\section{Introduction}

Atrial fibrillation is a relatively uncommon but dangerous complication of pregnancy. Emergency physicians must know how to treat both stable and unstable tachycardias in late pregnancy. In this case, a 40 -year-old female with a cerclage due to incompetent cervix and previous preterm deliveries presents in new-onset atrial fibrillation.

\section{Case Report}

A previously healthy 40-year-old African American G2 P1 female with a 23-week twin gestation complicated by an incompetent cervix requiring a cervical cerclage presented to the emergency department with intermittent palpitations and shortness of breath for the past two months. The patient arrived via EMS complaining of persistent shortness of breath and palpitations for the past six hours. She was noted by EMS to have a tachydysrhythmia, atrial fibrillation with rapid ventricular response (RVR), and received two doses of diltiazem en route: $20 \mathrm{mg}$ and then another $25 \mathrm{mg}$ without rate control.

Upon arrival, the patient's shortness of breath had resolved but she continued to have palpitations. The patient denied dehydration, alcohol or caffeine use, lack of sleep, recent illness, or any other precipitating factors. Her past medical history was significant only for a previous preterm delivery at 20 weeks due to an incompetent cervix. She denied any cardiomyopathies, prior arrhythmias, or other structural heart diseases.

On physical exam, the patient was afebrile, normotensive, with a heart rate in the $130 \mathrm{~s}-140 \mathrm{~s}$, and a respiratory rate of 25-42. Abnormal physical exam findings included bilateral crackles in the lung bases and an irregularly irregular heartbeat. Fetal heart tones were observed in both fetuses.

Initial work-up included an EKG, CBC, CMP, UA with microscopy, chest X-ray, cardiac enzymes, D-Dimer, BNP, and thyroid studies. On EKG, rate was 142 and rhythm was atrial fibrillation with rapid ventricular response. The chest radiograph revealed cardiac hypertrophy and right greater 
than left perihilar opacities suggestive of pulmonary edema. Laboratory examination revealed mild leukocytosis and mild elevation of D-Dimer, with the remainder of the results within normal limits.

The patient was placed on a diltiazem drip, which was titrated to $15 \mathrm{mg} / \mathrm{hr}$ without successful rate control. Her heart rate remained in the 130 s and the rhythm continued to be atrial fibrillation with RVR. Digoxin was then added as a second agent, and discussions about the potential risks of cardioversion in pregnancy ensued. Fortunately, the patient converted to sinus rhythm before cardioversion became necessary. The digoxin was discontinued; the diltiazem was also discontinued after the patient subsequently developed hypotension.

The patient was admitted to hospital and was followed closely in an intermediate care unit by cardiology and OB/GYN. An ECHO was completed during her hospital admission that showed moderate left ventricular hypertrophy (LVH), and on further laboratory examination she appeared to likely have gestational diabetes. Due to her $\mathrm{LVH}$, flecainide was not recommended, and due to her pregnancy it was decided that aspirin would be used for anticoagulation. The patient was discharged with follow-up with cardiology, high-risk obstetrics, and maternal fetal monitoring for the remainder of her pregnancy.

\section{Discussion}

There are many physiologic changes that occur during pregnancy, including increased demands on the cardiovascular system. Physiologic changes in the cardiovascular system include peripheral vasodilation resulting in decreased systemic vascular resistance, requiring increased cardiac output. This increase in cardiac output is accomplished by an increase in ventricular end-diastolic volume, wall mass, and contractility, which creates an increase in stroke volume and heart rate. Due to these alterations, pregnant women are placed at higher risk for developing comorbidities such as cardiac arrhythmias that range from benign to life threatening $[4,5]$.

While most cases of atrial fibrillation in pregnancy are the result of an underlying cardiac arrhythmia or structural abnormality, there is a very small percentage of women who develop new-onset "lone" atrial fibrillation during their pregnancy. While these cases are known in the OB/GYN literature, their presentation and management in the emergency department have not previously been described in emergency medicine literature.

In evaluating new-onset "lone" atrial fibrillation in the pregnant woman, it is important to discern the etiology of the abnormality. The initial work-up should attempt to rule out cardiac conduction and structural abnormalities, as well as extracardiac etiologies such as pulmonary embolus, hyperthyroidism, electrolyte disturbances, and pharmacologic effects. This assessment should include an EKG, echocardiogram, serum electrolytes, thyroid studies, and urine drug screen. The EKG should reveal the diagnosis of atrial fibrillation as well as any other conduction abnormalities once the rate is controlled, and an echocardiogram will be able to evaluate any structural abnormalities that would predispose the patient to developing an arrhythmia. A thorough evaluation of medications as well as illicit drug use should be completed, as many pharmacologic agents are arrhythmogenic. If clinically indicated, an evaluation for pulmonary embolus should be completed using laboratory and radiologic evidence and therapy should be initiated [6].

Emergency department treatment is divided between pharmacologic and nonpharmacologic interventions for rate and rhythm control. The initial goal should be to control the rate; however, in order to maintain consistent blood-flow to the patient's end organs including the placenta, sinus rhythm should be restored as soon as possible. The European Society of Cardiology established guidelines in 2011 for management of cardiovascular diseases in pregnancy. Beta-blockers are the first choice for rate control of atrial fibrillation in pregnancy, followed by calcium-channel blockers. They recommend digoxin as well, with the caveat that digoxin blood concentrations are unreliable in pregnancy due to interference with immunoreactive serum components [7].

When choosing therapeutic interventions, adverse events to both mother and fetus must be taken into consideration, as many antiarrhythmic drugs are teratogenic. The FDA classifies the risk and benefits of medications during pregnancy as follows:

A: controlled studies showed no risk in the fetus in any trimester of pregnancy.

B: no evidence of risk in humans. The chance of fetal harm is remote.

C: the risk cannot be ruled out. There are no wellcontrolled clinical studies, and animal studies show risk to the fetus. Fetal damage is likely if the drug is administered during pregnancy, but the potential benefits could exceed the potential risk.

D: sure evidence of risk. However, the potential benefits of use of the drug may outweigh the potential risk.

$\mathrm{X}$ : contraindicated in pregnancy. Studies in animals or humans showed certain evidence or risk of fetal abnormality and clearly outweigh any benefit to the patient [8].

Table 1 shows the FDA classification and safety profile for the pharmacologic agents used in the emergency department treatment of atrial fibrillation, modified from Oishi and Xing [9].

Emergency physicians frequently encounter patients with atrial fibrillation that does not respond to pharmacologic intervention, and cardioversion is a common emergency department intervention. Pregnant women with unresponsive, new-onset "lone" atrial fibrillation are rare, and emergency physicians are likely not as conversant with the risks and benefits of cardioversion in this patient group. In hemodynamically unstable patients, in patients who are not responding to pharmacologic therapy, or whenever the risk of ongoing atrial fibrillation is considered high for the mother or the fetus cardioversion up to $400 \mathrm{~J}$ can be performed safely 
TABLE 1

\begin{tabular}{|c|c|c|c|c|c|}
\hline Drug & $\begin{array}{l}\text { Rate versus } \\
\text { rhythm control }\end{array}$ & $\begin{array}{c}\text { Class of } \\
\text { recommendation/level of } \\
\text { evidence }\end{array}$ & $\begin{array}{c}\text { FDA } \\
\text { category }\end{array}$ & Dosage & Adverse effects \\
\hline Beta-blockers & Rate & Class IIa/C & $\mathrm{C}$ & & \multirow{4}{*}{$\begin{array}{l}\text { Pregnancy: born small for } \\
\text { gestational age, preterm } \\
\text { birth, and perinatal } \\
\text { mortality [1]. General: } \\
\text { bradycardia, hypotension, } \\
\text { AV block, bronchospasm }\end{array}$} \\
\hline Esmolol & & & & $\begin{array}{l}\text { Loading: } 0.5 \mathrm{mg} / \mathrm{kg} \text { over } \\
1 \mathrm{~min} . \text { Maintenance: } \\
0.06-0.2 \mathrm{mg} / \mathrm{k} / \mathrm{min}\end{array}$ & \\
\hline Metoprolol & & & & $\begin{array}{l}2.5-5 \mathrm{mg} \text { bolus over } \\
2 \mathrm{~min} \text {, up to } 3 \text { doses }\end{array}$ & \\
\hline Propranolol & & & & $0.15 \mathrm{mg} / \mathrm{kg}$ & \\
\hline $\begin{array}{l}\text { Nondihydropyridine } \\
\text { calcium channel } \\
\text { blockers }\end{array}$ & Rate & Class IIa/C & $\mathrm{C}$ & & \multirow{3}{*}{$\begin{array}{l}\text { Pregnancy: increased risk } \\
\text { of neonatal seizures, } \\
\text { jaundice, and hematologic } \\
\text { disorders [2]. General: } \\
\text { hypotension, heart failure }\end{array}$} \\
\hline Diltiazem & & & & $\begin{array}{l}\text { Loading: } \\
0.25 \mathrm{mg} / \mathrm{kg} / \text { dose over } \\
2 \mathrm{~min} \text {; may give a second } \\
\text { dose at } 0.35 \mathrm{mg} / \mathrm{kg} / \mathrm{dose} \text {. } \\
\text { Maintenance: } \\
5-15 \mathrm{mg} / \mathrm{kg} \text { for }<24 \mathrm{hr} \text {. }\end{array}$ & \\
\hline Verapamil & & & & $\begin{array}{l}0.075-0.15 \mathrm{mg} / \mathrm{kg} \text { over } \\
2 \mathrm{~min}\end{array}$ & \\
\hline
\end{tabular}

Cardiac glycoside

\begin{tabular}{|c|c|c|c|c|c|}
\hline \multicolumn{6}{|c|}{ Cardiac glycoside } \\
\hline Digoxin & Rate & Class IIb/C & $\mathrm{C}$ & $\begin{array}{l}\text { Loading: } 0.25 \mathrm{mg} \text { IV } \\
\text { every } 2 \mathrm{~h} \text {, up to } 1.5 \mathrm{mg} \text {. } \\
\text { Maintenance } \\
0.125-0.375 \mathrm{mg} \text { daily IV } \\
\text { or orally }\end{array}$ & $\begin{array}{l}\text { Pregnancy: digitalis toxicity } \\
\text { may cause fetal demise [3]. } \\
\text { General: digitalis toxicity, } \\
\text { heart block }\end{array}$ \\
\hline \multicolumn{6}{|c|}{ Class I C antiarrhythmic agent } \\
\hline Flecainide & Rhythm & Class IIb/C & $\mathrm{C}$ & & $\begin{array}{l}\text { General: heart block, } \\
\text { ventricular arrhythmias, } \\
\text { and heart failure }\end{array}$ \\
\hline \multicolumn{6}{|c|}{ Class III antiarrhythmic agent } \\
\hline Ibutilide & Rhythm & Class IIb/C & $\mathrm{C}$ & $\begin{array}{l}1 \mathrm{mg} \text { IV; may repeat dose } \\
\text { if no response after } \\
10 \mathrm{~min}\end{array}$ & $\begin{array}{l}\text { General: bradycardia, AV } \\
\text { block, Torsades }\end{array}$ \\
\hline \multicolumn{6}{|c|}{ Adjunctive therapies } \\
\hline Magnesium & & NA & $\mathrm{B}$ & $2 \mathrm{~g}$ over $15 \mathrm{~min}$ & $\begin{array}{l}\text { General: respiratory } \\
\text { depression }\end{array}$ \\
\hline
\end{tabular}

at all stages of pregnancy [6]. It is a Class I recommendation with a $\mathrm{C}$ level of evidence [9]. That is, risk to the fetus cannot be ruled out. While maternal cardioversion is unlikely to have significant effects on the fetus due to a high threshold for arrhythmogenesis and the minimal amount of current that reaches the uterus [10], continuous fetal monitoring should be utilized during the procedure, and cardioversion should be performed in a facility with the ability to perform an emergency C-section if needed. Previous reports note fetal arrhythmia developing as bradycardia or loss of variability after maternal cardioversion; both of which are indications for C-section [11].

In cases of atrial fibrillation occurring for longer than 48 hours, a transesophageal ECHO should be completed to evaluate atrial thrombus, and anticoagulation should be initiated prior to cardioversion $[6,8]$. Vitamin $\mathrm{K}$ agonists, however, are teratogenic and therefore unfractionated or low molecular weight heparin should be used during the first trimester. During the third trimester, frequent laboratory testing is recommended to maintain appropriate levels of anticoagulation $[8,12]$.

3.1. "Why Should Emergency Physicians Be Aware of This?" New-onset atrial fibrillation is rare in pregnancy but can increase the mortality and morbidity of the mother and fetus if not treated promptly. In the case of an unstable patient, cardioversion should be completed as quickly as possible. In a stable patient, effort should be made to determine the etiology of the arrhythmia, and treatment should follow accordingly. In the emergency department pharmacological intervention should be targeted toward rate control with Beta-blockers, calcium-channel blockers, or digoxin. In the case of our patient, management with diltiazem and digoxin was within European Society of Cardiology guidelines. Strict adherence 
to guidelines would have included beta-blocker as a first line medication. Once the rate is controlled, the provider should attempt to restore sinus rhythm chemically or electrically. In this case, the patient may require anticoagulation prior to cardioversion, with unfractionated or low molecular weight heparin. A high-risk obstetrician for the remainder of their pregnancy should follow these patients, and continued monitoring and treatment of her arrhythmia should be performed in conjunction with a cardiologist.

\section{Conflict of Interests}

The authors declare that there is no conflict of interests regarding the publication of this paper.

\section{References}

[1] K. M. Petersen, E. Jimenez-Solem, J. T. Andersen et al., “ $\beta$ Blocker treatment during pregnancy and adverse pregnancy outcomes: a nationwide population-based cohort study," The British Medical Journal Open, vol. 2, no. 4, Article ID e001185, 2012.

[2] R. L. Davis, D. Eastman, H. McPhillips et al., "Risks of congenital malformations and perinatal events among infants exposed to calcium channel and beta-blockers during pregnancy," Pharmacoepidemiology and Drug Safety, vol. 20, no. 2, pp. 138-145, 2011.

[3] H. L. Tan and K. I. Lie, "Treatment of tachyarrhythmias during pregnancy and lactation," European Heart Journal, vol. 22, no. 6, pp. 458-464, 2001.

[4] C. C. Burt and J. Durbridge, "Management of cardiac disease in pregnancy," Continuing Education in Anaesthesia, Critical Care and Pain, vol. 9, no. 2, pp. 44-47, 2009.

[5] J. A. Joglar and R. L. Page, "Management of arrhythmia syndromes during pregnancy," Current Opinion in Cardiology, vol. 29, no. 1, pp. 36-44, 2014.

[6] L. T. A. Dicarlo-Meacham and L. J. Dahlke, "Atrial fibrillation in pregnancy," Obstetrics and Gynecology, vol. 117, no. 2, pp. 489492, 2011.

[7] V. Regitz-Zagrosek, C. Blomstrom Lundqvist, C. Borghi et al., "ESC Guidelines on the management of cardiovascular diseases during pregnancy," European Heart Journal, vol. 32, no. 24, pp. 3147-3197, 2011.

[8] A. Perez-Silva and J.-L. Merino, "Tachyarrhythmias in pregnancy," ESC Council for Card Practice, vol. 9, no. 31, 2011.

[9] M. L. Oishi and S. Xing, "Atrial fibrillation: management strategies in the emergency department," Emergency Medicine Practice, vol. 15, no. 2, pp. 1-28, 2013.

[10] R. A. Desilva, T. B. Graboys, P. J. Podrid, and B. Lown, "Cardioversion and defibrillation," American Heart Journal, vol. 100, no. 6, part 1, pp. 881-895, 1980.

[11] E. J. Barnes, F. Eben, and D. Patterson, "Direct current cardioversion during pregnancy should be performed with facilities available for fetal monitoring and emergency caesarean section," British Journal of Obstetrics and Gynaecology, vol. 109, no. 12, pp. 1406-1407, 2002.

[12] S. M. Bates, I. A. Greer, I. Pabinger, S. Sofaer, and J. Hirsh, "Venous thromboembolism, thrombophilia, antithrombotic therapy, and pregnancy: American College of Chest Physicians evidence-based clinical practice guidelines (8th edition)," Chest, vol. 133, no. 6, pp. 844-886, 2008. 


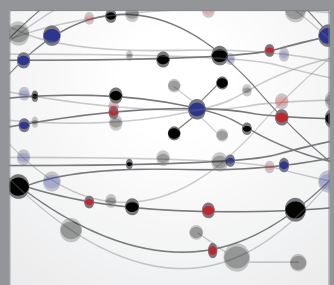

The Scientific World Journal
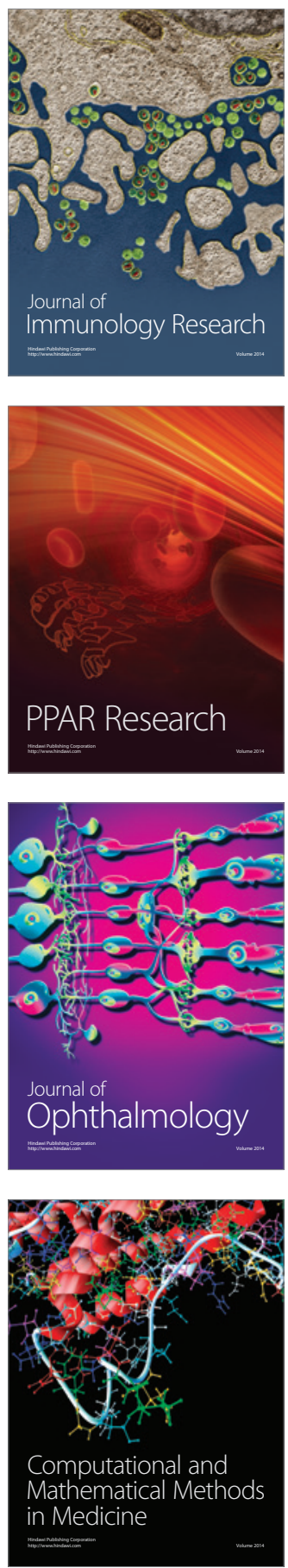

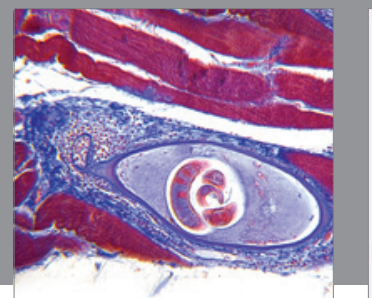

Gastroenterology

Research and Practice
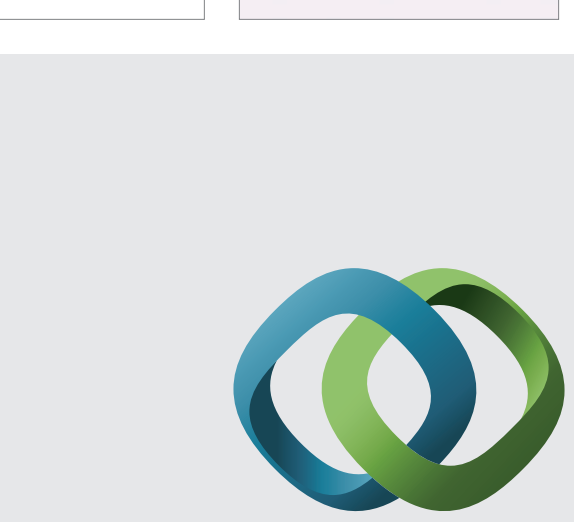

\section{Hindawi}

Submit your manuscripts at

http://www.hindawi.com
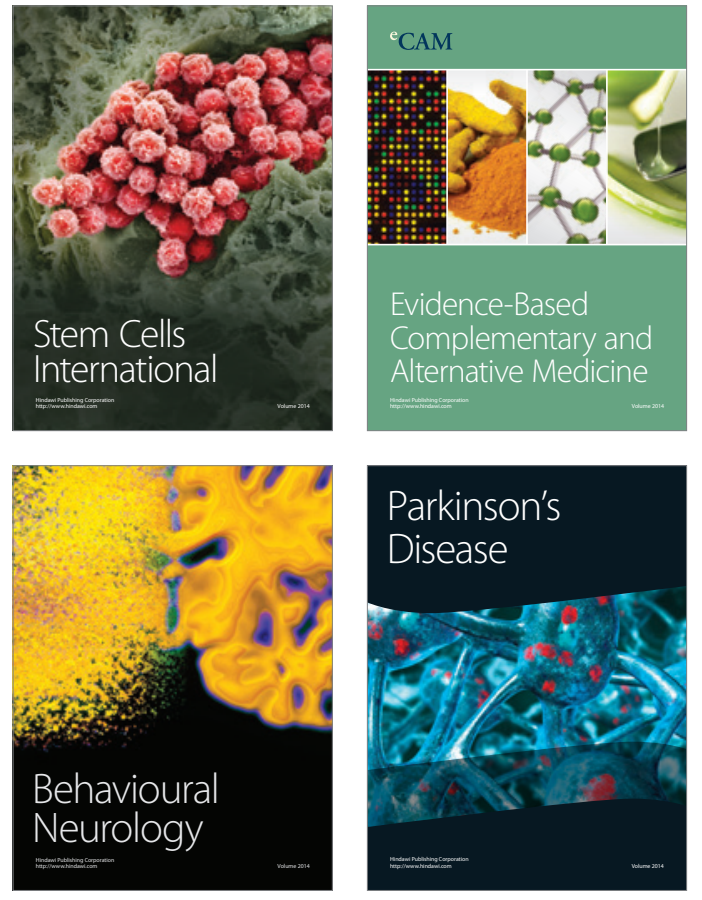
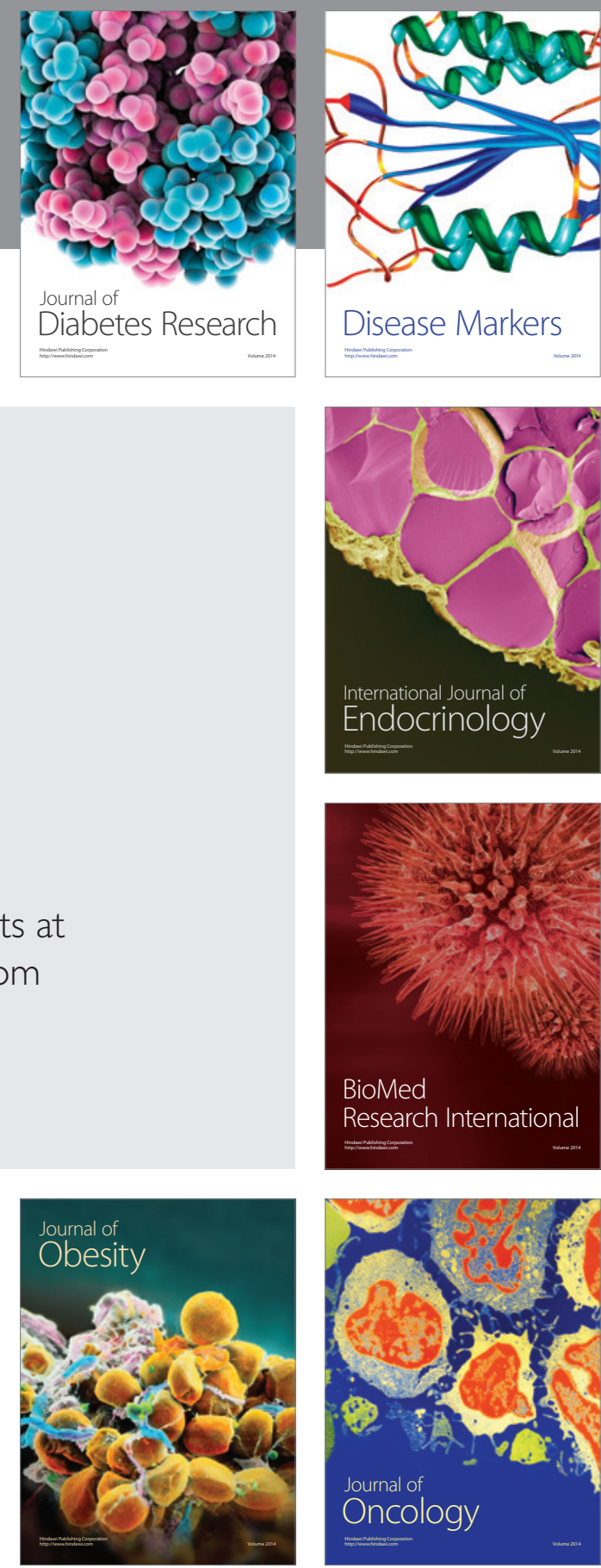

Disease Markers
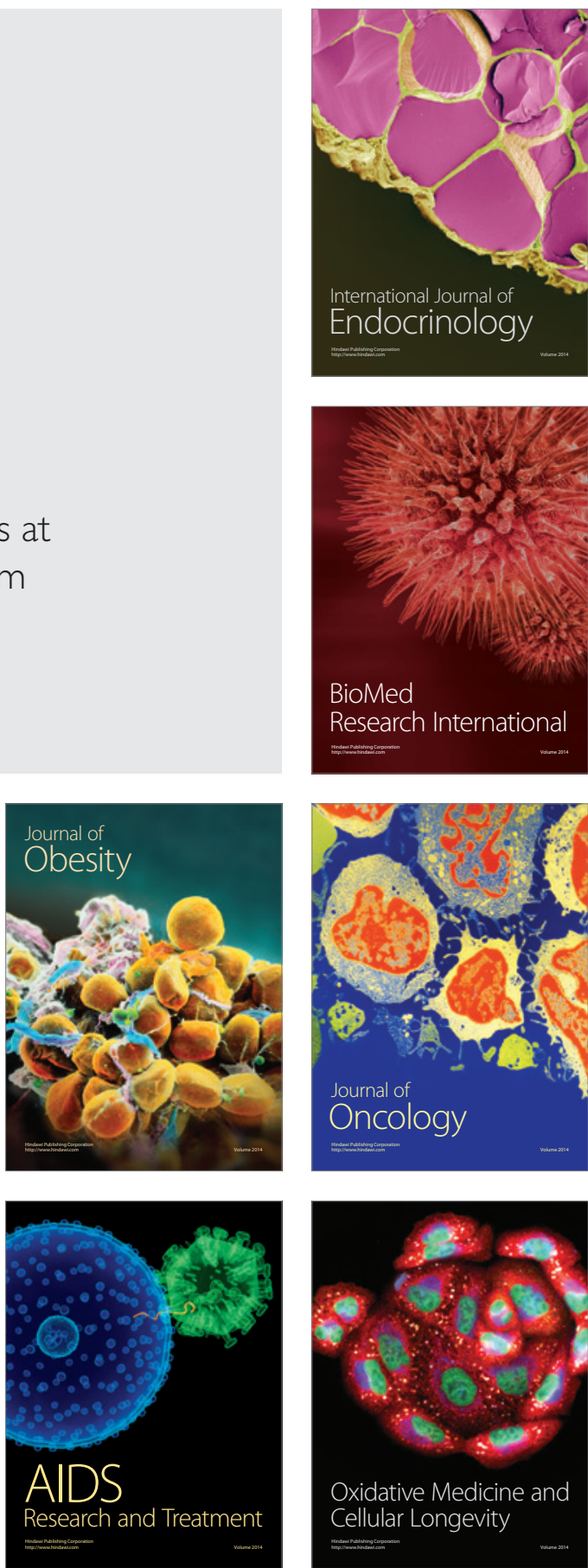